\section{Incidence and Performance of Invasive Airway Management in the German Air Rescue System H. Kuhnigk; ${ }^{1}$ K. Zischler;2 P. Sefrin ${ }^{1}$}

1. University of Wuerzburg, Department of Anesthesiology, Wuerzburg, Germany 2. St. Markus Hospital, Department of Anesthesiology, Frankfurt/M, Germany

Introduction: In case of unsuccessful intubation or inability to ventilate, invasive methods like cricothyrotomy, tracheotomy, and retrograde intubation are proposed for prehospital airway management. In physician equipped rescue systems, no data are available on the incidence and performance of these procedures in the field.

Methods: In a retrospective study, all 50 physicianequipped, German air rescue bases were asked to complete a questionnaire about invasive airway management from 1991 to 1995.

Results: Twenty-eight bases (56\%) answered. They reported a total of 128,202 emergency missions. The overall incidence of invasive airway management was $0.019 \%(n=24)$, of cricothyrotomy $0.016 \%(n=20)$, of tracheotomy $0.0024 \%(\mathbf{n}=3)$, retrograde intubation $0.0008 \%(n=1)$, and of tracheal puncture $0 \%(n=0)$, each after failed intubation attempts due to maxillofacial trauma $33 \%(n=8)$, laryngeal trauma $29.1 \%(n=7)$, soft tissue swelling $20 \%(n=5)$, and obstruction by foreign material $16.6 \%(n=4)$. One cricothyrotomy failed due to hemorrhage. Procedures were performed mainly by anesthesiologists $(45.6 \%, \mathrm{n}=11)$ or surgeons $(41.6 \%, \mathrm{n}$ $=10)$. Survival rate was $37.5 \%(n=9) .25 \%(n=6)$ of the patients died on scene, on transportation $8.3 \%(\mathrm{n}=$ $2)$, or in hospital $20.8 \%(n=5)$.

Conclusion: Invasive airway management has a low incidence in a physician equipped rescue system. Preferred technique is cricothyrotomy. Corresponding severe injuries must be expected for poor outcome although a patent airway was established.

Key Words: air-rescue; cricothyrotomy; invasive airway management

\section{Casualty Management Planning for Mass Crowd Events \\ Eric W. Williams \\ Medical Displan Victoria, Fitzroy, Victoria, Australia}

Incidents of mass casualties occurring at crowded events over recent years, have highlighted the need for effective planning to address the health implications associated with the staging of preplanned events, and to have inplace, an effective response medical organization to cope with an impact disaster in crowded situations. Health Emergency planning for special major events, must be integrated comprehensively with community emergency service response plans. Planning committees must include representatives from the event-approving authority who can impose specifications on entrepreneurs as a prerequisite to granting approval to stage the events. Such plans would include Public Health requirements for safe food and water, and adequate toilet accommodations, to prevent and reduce illness and dis- ease, and the requirement for a structured First-Aid system to be in place during the event.

This presentation will highlight the various considerations needed to prevent or reduce the effects of the public health aspects causing illness. It will address the on-scene requirements for a medical/first-aid organization to cope with minor casualties which can be expanded to provide rapidly prehospital medical control for the management of the more serious casualties.

Key Words: crowds; management; mass casualty

\section{Life-Saving Potential In Tsunami Victims}

Y. Watob, ${ }^{1}$ T. Kai; ${ }^{2}$ E. Pretto; ${ }^{3}$ J. Abrams, ${ }^{3}$ R. Saenz; ${ }^{3}$

H. Hirotsune, ${ }^{3} M$. Matsuzaka; ${ }^{2}$ M. Ikezoe; ${ }^{2}$

M. Wakasa; ${ }^{2}$ A. Sbimomura; ${ }^{2}$ A. Tada; ${ }^{2}$ M. Ota ${ }^{2}$

M. Aono 1

1. Department of Anesthesiology, Kanazawa Medical University, Ishikawa, Japan; 2. Senri Critical Care Medical Center, Suita, Osaka, Japan; 3. Safar Center for Resuscitation (SCRR), University of Pittsburgh, Pittsburgh, Pennsylvania, USA

Introduction: There have been few reports concerning the health and medical effects of an earthquake-tsunami disaster. On 12 July, 1993 at 22:17 hours local time, an earthquake ( 7.8 on Richter Scale) hit Okushiri Island, Hokkaido, Japan. The earthquake generated several tsunamis which hit the shore of the island within 3 to 5 minutes after the impact. Total deaths on Okushiri Island (pop. 4,000) were 203 with 29 missing and 236 injured.

Methods: A joint Japan and USA research team performed a structured-interview study in Aonae and Matsue districts of Okushiri Island, 3 months after the event. The team performed 91 interviews and encountered 11 survivors directly hit by the tsunami. The team also analyzed medical records of victims and official reports concerning the medical response.

Results: In Aonae and Matsue, 113 deaths were identified as having been caused by the tsunami. Of these, 89 cases were due to drowning and 22 were caused by lifethreatening injuries (head, 16; spine, 3 ; chest, 2; hemorrhage, 1). The causes of two deaths were unknown. Among the drowning victims, the diagnosis was made by the existence of water in the airway and/or respiratory system, by chest $x$-ray, or autopsies. Nine survivors were rescued by fishermen's boats or patrol ships of the Maritime Safety Agency within four hours after the impact. Two survivors came back to shore by themselves. Some of the survivors testified anecdotally that they had heard the voices of other victims in the dark sea when they were drifting (the water temperature was $24^{\circ} \mathrm{C}$ ). Data analysis among victims indicated that age, gender, and prior physical injury are risk factors for drowning in a tsunami. This study also indicates that some victims can survive even after being directly hit by a tsunami.

Conclusions: Therefore, sea and land rescue are warranted immediately after the impact of an earthquaketsunami.

Key Words: earthquake; search and rescue; tsunami 